REVISTA DE DERECHO UNED, núm. 2, 2007

\title{
PROTECCIÓN A LA INFANCIA EN LA LEGISLACIÓN ESPAÑOLA. ESPECIAL INCIDENCIA EN LOS MALOS TRATOS (PARTE GENERAL)
}

\author{
Por Isaac Ravetllat Ballesté \\ Prof. Asociado de Derecho Civil de la Facultad de Derecho \\ de la Universidad de Barcelona \\ Prof. Tutor de la Universidad Nacional de Educación a Distancia \\ Prof. Escuela Universitaria de Trabajo Social \\ y Educación Social Pere Tarrés \\ Investigador del Instituto de Infancia y Mundo Urbano (CIIMU)
}

\begin{abstract}
Resumen: La discriminación sobre la infancia, su explotación económica y el fenómeno del maltrato infantil en todas sus manifestaciones han sido una constante en nuestra historia. El presente estudio trata de elaborar una línea de argumentación sobre el fenómeno del maltrato infantil y el tratamiento legal que dicha figura recibe por parte de nuestro ordenamiento jurídico. Así, para dar respuesta a dicha situación, el Derecho plantea la posibilidad de utilizar dos caminos para la reglamentación de las conductas provocadoras de maltrato. La sanción en el ámbito penal buscando la reprensión del causante, y la protección en el ámbito civil propiciando la ayuda y superación de la situación a la víctima menor de edad.
\end{abstract}

Palabras clave: infancia, maltrato, protección, desamparo, riesgo social

Abstract: Discrimination against children, their exploitation, and the maltreatment of minors in all it forms has been a recurrent theme throughout history. This paper focuses on the ill-treatment of children and the protection and remedies that our legal system sets forth in this area. There are two possible legal approaches with regards to 
behaviours that may cause ill-treatment: criminal law tend to punish the offending party, while private law concentrates on protection and seeks to help the underage victim overcome the situation.

Sumario: 1. LA INFANCIA COMO CATEGORÍA SOCIAL.-1.1. Consideraciones iniciales.-1.2. Evolución a lo largo de los tiempos.-2. LA CONVENCIÓN SOBRE LOS DERECHOS DEL NIÑO.-4.1. Antecedentes.-4.1. La Convención sobre los Derechos del Niño: génesis y caracteres.-3. LA PROTECCIÓN DE LA INFANCIA EN EL ORDENAMIENTO JURÍDICO ESPAÑOL.-3.1. Introducción.-3.2. La Constitución de 1978.-3.2.1. Caracteres generales y tratamiento de los derechos de la infancia en el texto constitucional.-3.2.2. Competencia normativa en materia de protección a la infancia.-3.2.3. El modelo constitucional de protección a la familia y al menor.-3.3. Las Leyes reformadoras del derecho de la persona y de la familia del período 1981-1987.-3.4. La Ley Orgánica 1/1996, de 15 de enero, de protección jurídica del menor.-4. BIBLIOGRAFÍA

\section{LA INFANCIA COMO CATEGORÍA SOCIAL}

\subsection{CONSIDERACIONES INICIALES}

La infancia es, sin duda, en nuestra conceptualización actual un período válido por sí mismo. Está constituida por un grupo en edad vulnerable que es preciso proteger. El objeto de esta protección y cómo se organiza la misma, depende, entre otras cosas, de la concepción que socialmente se tenga de la misma.

El concepto infancia dista mucho de ser objetivo o universal. Por una parte, porque cada sociedad, cada cultura, cada forma de vida, define explícita o implícitamente qué debe entenderse por infancia, cuáles son sus características, y, en consecuencia, qué períodos de la vida incluye. Por otra parte, diversos historiadores y otros estudiosos ${ }^{1}$

${ }^{1}$ En Francia destaca la obra de Philippe Ariès, uno de los primeros autores contemporáneos en emprender un estudio profundo sobre la aparición y posterior evolución del concepto infancia (vid. ARIÈS, Philippe, "El niño y la vida familiar en el Antiguo Régimen», versión castellana de Naty García Guadilla, Ed. Taurus, Madrid, 1987). En el ámbito anglosajón resaltar las aportaciones de Lloyd Demause, psicólogo norteameriacano que puso en tela de juicio las teorías de Philippe Ariès (vid. DEMAUSE, Lloyd, "Historia de la Infancia», Ed. Alianza Universidad, Madrid 1982). Finalmente en España, autores como Buenaventura Delgado, Dolors Renau i Manen, 
nos han mostrado cómo en diferentes momentos históricos de una misma cultura el significado del concepto también ha ido cambiando ${ }^{2}$.

Lo anterior nos lleva a afirmar que el concepto niño/a no es natural, sino cultural, histórico, aunque sobre una base natural, y por tanto varía culturalmente la percepción que se tiene sobre él ${ }^{3}$. No hay, así, que considerar estrictamente natural lo que a lo sumo es normal en nuestra propia cultura a modo de producto social histórico.

Entendemos, en definitiva, que no hay una realidad intangible que podamos asociar con el término "niño/a» o con el concepto «infancia", un ser y un estado esencial que esperan ser descubiertos, definidos y realizados, de manera que podamos cuestionarnos y decir a los otros «así es como son los/as niños/as, esto es la infancia». Existen, por el contrario, multiplicidad de niños y de infancias, cada uno construido, elaborado e interpretado por «nuestras propias concepciones sobre la infancia y de lo que los niños son o deberían ser".

De acuerdo con lo anterior, a lo largo de la historia de la humanidad la concepción que la gente ha tenido respecto de los niños y las niñas ha ido evolucionando. Así, la noción de infancia que hoy en día tenemos y que nos parece una evidencia fuera de toda duda, no ha existido ni mucho menos a lo largo de todos los tiempos, sino que por el contrario es una creación reciente, que emerge definitivamente sólo después de la revolución industrial. La idea, por ejemplo, de que el niño o la niña es un sujeto de derechos no quedará plasmada en la normativa internacional hasta la aprobación por la Asamblea General de las Naciones Unidas de la Convención de los Derechos del Niño el 20 de noviembre de 1989.

Estos cambios en las actitudes y en las instituciones relacionadas con la infancia no se han ido desarrollando de forma aislada o fortuita; sino que, por el contrario, hay que comprenderlos como resultados de procesos sociales más amplios, de índole económica y política.

Montserrar Roig, José Leal Rubio y Pedro Voltes, han realizado sus pequeñas aportaciones a la bibliografía especializada sobre el tema.

2 CYRULNIK, Boris, «Los patitos feos. La resiliencia: una infancia infeliz no determina la vida», Ed. Gedisa, Barcelona, 2002, pág. 112, afirma que las culturas se pasan la vida cambiando y cuando no cambian, mueren.

3 LINAZA, Josetxu, "Desarrollo, educación y derechos de la infancia", en Infancia y Sociedad, n. ${ }^{\circ} 27-28$, Octubre 1994, pág.45, defiende que la noción misma de infancia es un invento social para lograr una mejor adaptación de los seres humanos a medios muy diversos. 


\subsection{EVOLUCIÓN A LO LARGO DE LOS TIEMPOS}

El concepto de infancia como categoría psicosociológica comienza a esbozarse con claridad a mediados del siglo XVI, y no cobrará fuerza hasta mitades del siglo XVIII, cuando se logra establecer una relación de causalidad entre la posibilidad de supervivencia del niño y los cuidados que se le prodigan ${ }^{4}$.

Este reconocimiento de la infancia está íntimamente ligado a la instauración de la familia moderna; institución basada, en términos generales, en la idea del amor conyugal; en el reconocimiento discriminado de los roles parentales y filiales; en la instauración de un derecho sucesorio como garantía de transmisión de los bienes personales y en la preocupación por la salud y educación de sus miembros.

Para el historiador francés Philippe Ariès el pasaje desde la indiferencia y el desapego afectivo por los niños, al apego afectivo y preocupación por su suerte, más propio de la vida moderna, se apoyó en otro cambio social significativo: el de la separación de la vida privada de la vida pública. En la medida en que las relaciones familiares pasaron a desarrollarse en la intimidad y privacidad de la casa, y ésta dejó de ser un lugar abierto, una prolongación de la vida social en la calle, cambió la relación entre los miembros de la familia y, por ende, entre los padres y los hijos.

Los niños, hasta finales del siglo XIx habían sido vendidos, encarcelados, torturados, utilizados en trabajos durísimos desarrollados en el interior de las minas y de las fábricas como consecuencia del proceso de industrialización. Fue durante esa época que empezó a surgir la concepción del menor como sujeto digno de protección. En la consecución de dicho logro participaron de forma importante las aportaciones realizadas por las ciencias sociales, especialmente por la psicología, la pedagogía y la sociología.

No obstante, habrá que esperar hasta el siglo xx para que la infancia sea tenida en cuenta como tal. El hecho más relevante acaecido durante el pasado siglo fue, sin duda, la aprobación por las Naciones Unidas, en 1989, de la Convención sobre los Derechos del

${ }^{4}$ A este respecto COTS i MONER, Jordi, «La Declaració Universal dels Drets de l'Infant», Estudis Rosa Sensat, Edicions 62, Barcelona, 1979, pág. 33, afirma que en el siglo XVIII empieza a concretarse un cambio de actitud con respecto a la infancia. Y añade a continuación que Jean J. Rousseau, con su tratado de pedagogía «Emile» (publicado en 1762) es el símbolo de ese cambio. 
Niño que encuentra sus antecedentes en la Declaración de los Derechos del Niño aprobada, en 1959, y en la denominada Declaración de Ginebra, aprobada en 1924. Frente a las dos anteriores, la Convención de 1989 aporta dos grandes novedades. En primer lugar no es ya un texto meramente declarativo de principios genéricos - la Declaración de Ginebra enunciaba cinco, y la Declaración de 1959 incluía diez - sino un instrumento jurídico vinculante; en segundo lugar, la concepción exclusivamente tuitiva, es sustituida por una nueva y distinta concepción que afirma que el niño es sujeto de derechos. El niño es, para la Convención, un sujeto en desarrollo, pero un sujeto de derechos, y no sólo de derechos pasivos, es decir derechos a recibir prestaciones de los adultos, sino también de derechos activos como la libertad de conciencia, pensamiento y religión, la libertad de expresión e información, la libertad de asociación y reunión o el derecho de participación. En otras palabras, cabe decir que la Convención termina con aquella vieja concepción del niño/a de ser visto como los aún-no —aún-no adultos, aún-no responsables, aún-no capaces, aúnno competentes, aún-no fiables, aún-no con los mismos derechos; aún-no dignos de ser escuchados frente a la categoría de los adultos representada por la idea de los ya-si ${ }^{5}$.

\section{LA CONVENCIÓN SOBRE LOS DERECHOS DEL NIÑO}

De acuerdo con lo anterior, desarrollamos a continuación los que consideramos como aspectos más relevantes de la norma que representó ese punto de inflexión positivo en el tratamiento legal de la infancia, destacando en primer lugar cuáles fueron sus antecedentes, para posteriormente resaltar las características fundamentales de dicho documento internacional.

\subsection{ANTECEDENTES}

Los primeros intentos de creación de una asociación internacional para proteger a la infancia aparecieron en el año 1913, pero la Primera Guerra Mundial impidió su consolidación, que finalmente se produjo el año 1921 en Bruselas. La Cruz Roja había creado en el año 1920 en Ginebra, la Unión Internacional de Socorro a los Niños, con

5 VERHELLEN, Eugeen, "Convention on the Rights of the Child», Garant Publishers, Gent, 1997, pág. 16, que recoge en nuestro entorno CASAS, Ferran, «Infancia: perspectivas psicosociales», Ed. Paidós, Barcelona, 1998, pág. 33 
atenciones especiales en tiempos de guerra, y proclamaba la Declaración de los Derechos del Niño el 24 de septiembre de 1924 (firmada y conocida como la Declaración de Ginebra).

La Declaración de Ginebra fue una obra personal de la inglesa Eglantyne Jebb, fundadora el año 1919 de la asociación inglesa Save the Children Fund (SCF) y promotora el año siguiente de la Union Internationale de Secours aux Enfants (UISE).

La Declaración consiste en un documento breve, simple y redactado en un lenguaje directo que recoge las necesidades más elementales de la infancia.

El futuro que habría podido tener la Declaración de Ginebra se vio frustrado por el estallido de la Segunda Guerra Mundial. Finalizado este conflicto, y teniendo muy recientes sus dramáticas consecuencias, las Naciones Unidas elaboraron la Declaración Universal de los Derechos Humanos (1948).

También una vez finalizada la Segunda Guerra Mundial, las Naciones Unidas quisieron redactar su propia Carta para la infancia, y el día 20 de noviembre de 1959 la Asamblea General de las Naciones Unidas aprobó la Declaración Universal de los Derechos del Niño -Resolución 1386 (XIV) de la Asamblea General de las Naciones Unidas, de 20 de noviembre de 1959-. Dicha declaración aunque parte de los principios anteriormente adoptados -en la Declaración de Ginebra-, es más progresiva en sus contenidos, no sólo porque refleja la evolución considerable que se había producido desde el año 1924 en el campo de la protección a la infancia, sino que, además, fue completada con otros principios que transformaron dicho documento en una verdadera Carta de las Naciones Unidas.

\subsection{LA CONVENCIÓN SOBRE LOS DERECHOS DEL NIÑO: GÉNESIS Y CARACTERES}

El 20 de noviembre de 1989, la Asamblea General de las Naciones Unidas adoptó, por unanimidad, la Convención sobre los Derechos del Niño, quedando abierta a la firma de los Estados el 20 de enero de 1990 y entrando en vigor el 2 de septiembre del mismo año.

El texto, gestado a partir de las propuestas del Gobierno polaco se estructura en tres partes: el Preámbulo, que esboza los principios básicos fundamentales; el articulado, que define las obligaciones de los Estados Partes y, por último, las disposiciones de ejecución, que 
establecen, además de las condiciones para su entrada en vigor, la forma de verificarse y promoverse el cumplimiento de la Convención. De manera general podemos afirmar que las características más destacadas de la Convención son las siguientes:

Se trata de un documento con fuerza jurídica obligatoria. Así, cuando un Estado ratifica el texto de la Convención queda automáticamente vinculado al cumplimiento de su contenido. El carácter vinculante ha de entenderse íntimamente conectado con la consideración del menor como ser autónomo: el hecho de que el instrumento que recoge sus derechos sea un instrumento jurídico, y no una declaración de buenas intenciones, indica que las pretensiones que puedan tener los niños para la protección de sus derechos no sólo interesan a la humanidad en general, sino que vinculan a los Estados signatarios de la Convención. Este último inciso se completa con la consideración de este tratado internacional como una norma self-executing --de ejecución inmediata-. La aplicabilidad directa de las normas de la Convención en el ordenamiento jurídico español se produce, por tanto, sin necesidad de medidas normativas de desarrollo.

Nos ofrece una imagen global de la infancia. A diferencia de lo que hemos visto que sucedía en la Declaración de Ginebra de 1924 y en la Declaración Universal de los Derechos del Niño de 1959, instrumentos internacionales que se limitaban a incidir en la infancia en situación de riesgo, la Convención de las Naciones Unidas del año 1989 está dirigida a toda la infancia, como grupo social universal, estableciendo los derechos que les asisten en los diferentes ámbitos.

Se produce un pleno reconocimiento del niño/a como verdadero "sujeto de derechos». Desde el campo de la psicología social se considera que el texto de la Convención instaura el conocido como principio de las tres « $\mathrm{P}(\mathrm{s})$ ): protección, provisión y participación ${ }^{6}$.

Con anterioridad a la adopción de éste instrumento internacional por parte de la Asamblea General de las Naciones Unidas, el/la niño/a venía siendo considerado/a tan solo como un "objeto" (pasivo) de protección, ya que se consideraba que tan sólo se debía intervenir si era evidente que sucedía algo negativo. Nos movíamos, por tanto, dentro del campo de la "protección", o de los denominados «derechos de supervivencia».

${ }^{6}$ Dicho principio es introducido por Verhellen y seguido en nuestro país por Ferran Casas. VERHELLEN, Eugeen, "Convention on the Rights of the Child», Garant Publishers, Gent, 1997, págs. 80-81. CASAS, Ferran, «Infancia: perspectivas psicosociales», Ed. Paidós, Barcelona, 1998, pág. 219. 
Que niños y niñas adquieran pleno estatus social como sujetos de derechos, implica un profundo cambio de perspectiva; no sólo tienen derecho a ser protegidos, a ser atendidos de sus problemas y ante sus carencias, sino que también tienen derechos civiles y políticos, claramente vinculados a las libertades básicas, y, en su promoción a la calidad de vida.

Otro concepto importante que introduce la Convención, y que ya había sido apuntado tímidamente en la Declaración Universal de los Derechos del Niño, es que todas las medidas respecto de la infancia deben estar basadas en la consideración del «interés superior del niño", convirtiéndose éste en el principio rector que debe orientar toda acción a favor del bienestar de la infancia -artículo 3.

\section{LA PROTECCIÓN DE LA INFANCIA EN EL ORDENAMIENTO JURÍDICO ESPAÑOL}

\subsection{INTRODUCCIÓN}

Nuestro Ordenamiento jurídico ha sido permeable, a las evoluciones producidas a nivel internacional. Así, un mero repaso de la normativa española posterior a la Constitución de 1978, nos muestra el efecto que provocó en nuestra legislación, estatal y autonómica, esa nueva sensibilidad que se venía gestando fuera de nuestras fronteras. Este movimiento legislativo coincidió en el tiempo con el despegue o expansión de las Comunidades Autónomas que en gran medida han ido marcando su "política» en lo que respecta a las políticas de infancia, a través de su actividad parlamentaria.

España, con la implantación del sistema democrático tras la desaparición del régimen franquista, podríamos decir que ha recorrido, en el iter de protección jurídica de las personas menores de edad, tres etapas fundamentales ${ }^{7}$ : 1) La Constitución de 1978; 2) las reformas del Código Civil iniciadas en 1981 e introducidas hasta 1987; 3) la Ley Orgánica 1/1996, de 15 de enero, de Protección Jurídica del Menor; amén de la rica normativa reciente tuitiva de los menores en las Comunidades Autónomas ${ }^{8}$.

7 Seguiremos las tres etapas marcadas por ALONSO PÉREZ, Mariano, «La situación jurídica del menor en la Ley Orgánica 1/1996, de 15 de enero, de protección jurídica del menor, de modificación del Código Civil y de la Ley de Enjuiciamiento Civil: luces y sombras", en Actualidad Civil, n.² 2, Enero 1997, págs. 20-22.

8 Vid. Tabla anexa con la normativa vigente a nivel autonómico en materia de protección a la infancia. 


\subsection{LA CONSTITUCIÓN DE 1978}

El análisis relativo a las fuentes del régimen jurídico de las personas menores de edad en España ha de partir, necesariamente, de lo dispuesto en nuestra norma fundamental, pues en ella se contienen, como sucede con el resto de la materia jurídica, sus enunciados o principios fundamentales.

Básicamente pueden apuntarse dos grandes contenidos relativos al régimen jurídico constitucional de la infancia en España. Por una parte, el catálogo de los derechos fundamentales en la medida en que son aplicables a los niños, niñas y adolescentes. Por otra, los títulos de distribución competencial entre los distintos entes territoriales, fundamentalmente Estado y Comunidades Autónomas -artículos 148 y 149 de la Constitución-. Todo ello enmarcado, además, dentro de la cláusula de Estado Social que define nuestro actual sistema político, cláusula que adquiere especial significación al referirse a la protección y derechos de la niñez.

\subsubsection{Caracteres generales y tratamiento de los derechos de la infancia en el texto constitucional}

La primera consideración que cabe hacer es que la regulación contenida en la Constitución de 1978 sobre esta materia es dispersa. No existe, pues, un precepto o bloque de disposiciones específicamente destinados a establecer las líneas esenciales del régimen jurídico de las personas menores de edad, sino que será preciso realizar un recorrido por el texto constitucional para ir componiendo las diversas normas básicas que conforman los presupuestos de la ordenación legal de esta materia.

Si nos detenemos en el catálogo constitucional de derechos fundamentales y libertades públicas - Sección Primera del Capítulo II del Título Primero- comprobaremos como el texto de la Carta magna no hace referencia explícita alguna a los sujetos de dichos derechos fundamentales -más allá de la distinción entre ciudadanos y extranjeros-. A pesar de ese silencio hay suficientes indicios como para afirmar que los derechos que se reconocen de manera general a "todos», deben entenderse igualmente referidos a los niñas, niñas y adolescentes, considerados como personas.

Por lo que a la mención específica de la infancia se refiere, el texto constitucional apenas reúne tres citas expresas a la misma. El ar- 
tículo 39.4 que establece que «los niños gozarán de la protección prevista en los acuerdos internacionales que velan por sus derechos», el artículo 20.4 que prevé como límite a la libertad de expresión «la protección de la juventud y de la infancia», y el artículo 27.1 referente al derecho a la educación que, obviamente, está dirigido al menor como sujeto paradigmático - aunque nada se diga al respecto- . El hecho de que "todos tengan derecho a la educación" y que las personas cuantitativamente más beneficiadas de este derecho sean niños y niñas - recordar que la escolarización obligatoria y gratuita hoy en día se extiende de los seis hasta los dieciséis años- nos lleva a afirmar plenamente que los menores de edad son los principales titulares de este derecho.

En definitiva, la Constitución además de impulsar las grandes reformas del Derecho de familia, hace del menor titular de una serie de derechos fundamentales, refuerza su valoración como persona y lo configura como un ser participativo y creador. También, el texto constitucional, al igual que los instrumentos internacionales de protección de los derechos del menor, en general, y la Convención sobre los Derechos del Niño en particular, sitúa a los progenitores como primeros responsables de la crianza y desarrollo de los hijos/as, y sólo de manera subsidiaria el Estado asumirá los deberes y las cargas que implica la asistencia y la educación de los menores - artículo 39 de la C.E.

\subsubsection{Competencia normativa en materia de protección a la infancia. Hacia un tratamiento autónomo progresivo de la materia}

El segundo gran bloque de aspectos relativos al estatuto del menor que se contienen en la Constitución se refiere a la distribución competencial entre los distintos niveles territoriales. Dicha distribución se ordena, principalmente, en los artículos 148 y 149 C.E., si bien hay que tener en cuenta otros preceptos del texto constitucional.

Así, sin abandonar todavía el marco constitucional de referencia, debe ponerse de relieve cómo tras un momento inicial en que un gran número de Estatutos de Autonomía - principios de los años ochenta - optaron por contemplar el ámbito de la protección a la infancia como un subapartado o anexo dentro del sector normativo propio de los servicios sociales, reproduciendo así el modelo imperante a finales del siglo XIX, la tendencia actual, en cambio, paulatinamente se ha venido alterado para pasar a contemplar dicha materia desde una perspectiva particular e individualizada. 
La transposición y el desarrollo efectuado de las previsiones constitucionales a las que acabamos de hacer mención por parte de los Estatutos de Autonomía de las distintas Comunidades Autónomas nos lleva a distinguir tres grandes grupos de normas estatutarias en virtud de cual haya sido la técnica legislativa empleada para asumir y hacer efectivas las competencias en el ámbito de la atención y la protección de los derechos de la infancia9.

El primero de ellos se caracterizaría por no contener un título competencial específico que habilite a la Comunidad Autónoma en cuestión para el desarrollo de la normativa de atención a la infancia y a la adolescencia, sino que, por el contrario, se vienen a emplear indistintamente los términos genéricos de asistencia, bienestar social y servicios sociales, asistencia social y desarrollo comunitario. En resumen, se prevé o engloba dicho ámbito de actuación dentro de lo que sería la política global de asistencia y bienestar social, desarrollando de este modo la previsión del ya mencionado artículo 148.1.20 CE. En este grupo se encuadraron inicialmente ${ }^{10}$ las Comunidades Autónomas de La Rioja, Cantabria, Asturias, Murcia, Aragón, Extremadura, Madrid, Castilla-León y Galicia. De todas ellas, actualmente, tan sólo Galicia mantiene sin desmembrar ese tronco común y presuntuosamente omnicomprensivo de la acción social. El resto de Comunidades Autónomas, superando ya la conocida como primera generación de normas sobre servicios sociales, han introducido, a través de sendas modificaciones de su normativa estatutaria, menciones específicas sobre el ámbito de la protección de la infancia, que vienen a fragmentar, a disgregar esa idea de política global, de sistema unitario que había impregnado toda la legislación social hasta esos momentos.

Un segundo conjunto englobaría aquellas Autonomías que lo plantean en un terreno amplio y genérico mezclado con otros conceptos. Éste sería el caso de la Comunidad Valenciana o Castilla-La Mancha, que hacen referencia a asistencia social y a servicios sociales y a instituciones públicas de protección y ayuda de menores, jóvenes, emigrantes, tercera edad, disminuidos y demás grupos o sectores sociales

9 Vid. GIMÉNEZ SALINAS, Esther, «Protección de menores» en "Comentarios del Estatuto de Autonomía de Cataluña», Vol. II, Ed. Instituto de Estudios Autonómicos, Barcelona, 1990, págs. 188-189.

10 Un estudio comparado de las disposiciones originarias relativas a la asunción de competencias en materia de asistencia social y servicios sociales por parte de los distintos Estatutos de Autonomía lo encontramos en MINISTERIO DE ADMINISTRACIONES PÚBLICAS, "Estatutos de Autonomía por materias», Ed. Ministerio para las Administraciones Públicas, Madrid, 1991, págs. 572-574. 
que requieren de una especial protección, incluida la creación de centros de protección, reinserción y rehabilitación. Parece también claro que, en este caso, dichos enunciados deben cohonestarse de nuevo con el artículo 148.1.20 CE.

Por último tres son los Estatutos de Autonomía que recogen de forma específica y unitaria la atribución de competencias en materia de atención y protección de la infancia y la adolescencia. Se trata de País Vasco, Cataluña y Andalucía.

\subsubsection{El modelo constitucional de protección a la familia y al menor}

Nuestra Constitución ha acogido en el artículo 39 un sistema de protección de la familia y salvaguarda de los menores calificado por la doctrina como mixto, o parcialmente público, basado en la colaboración entre el ámbito privado y el público ${ }^{11}$, en el sentido que las finalidades se cumplen por el Estado - sistemas de seguridad social, servicios sociales, organismos públicos de protección a la infancia, por ejemplo- y por los particulares - alimentos entre parientes, obligaciones propias derivadas de la filiación, pensiones en caso de separación/divorcio.

Así, el citado artículo 39 C.E. en sus cuatro apartados, diseña un programa constitucional, que trata de asegurar que toda persona menor de edad se desarrolle de manera plena y adecuada, interviniendo en el mismo dos tipos de fuerzas: la privada, a través de las obligaciones que la Constitución impone a la familia. Y la pública, mediante el desarrollo de la protección integral que se garantiza a los hijos y a aquellos que deben contribuir a alcanzarla de una manera efectiva.

11 Para ROCA i TRIAS, Encarna, «El nuevo derecho catalán sobre la familia», Revista Jurídica de Cataluña, $n^{\circ} 1,1999$, pág. 10, en el contexto constitucional, el artículo 39 C.E. establece un sistema calificado como mixto. Ello significa que la protección económica, social e incluso jurídica de la familia no queda limitada a los poderes públicos, sino que implica a los propios interesados, primordialmente a través de las obligaciones derivadas de la potestad, la tutela y los alimentos entre parientes. En este mismo sentido vid. ROCA i TRIAS, Encarna, "Familia, familias y Derecho de la familia", Anuario de Derecho Civil, n. ${ }^{\circ} 4,1990$, pág. 1056. También, ROCA i TRIAS, Encarna: "Familia y cambio social (De la casa a la persona)», Ed. Cuadernos Cívitas, Madrid, 1999, pág. 33, 66-68 y 222, defiende que el Derecho español no se basa en una contraposición sector público v, sector privado, sino en una cooperación entre ambos sectores, ya que las finalidades esenciales se obtendrán por medio de la atribución a cada uno de ellos de unas funciones específicas, en lo que se ha denominado sistema mixto. 
De esta forma, se concibe la actuación del Estado como un mecanismo de garantía de los derechos fundamentales de los ciudadanos, y es por ello que los poderes públicos no pueden restar indiferentes ante ciertos problemas, deben por el contrario, proveer soluciones y no dejar que sean los propios particulares los que de manera exclusiva los solventen. Éstos y el Estado deben colaborar, por tanto, de manera estrecha en alcanzar el grado de bienestar que corresponde $^{12}$. Así, el Derecho de familia ya no puede ser considerado como un sistema que afecte exclusivamente a intereses particulares, sino que, por el contrario, ha ido adquiriendo de manera paulatina un fuerte contenido público, con aspectos que se refieren tanto a la imperatividad de las normas que regulan los procesos relacionados con cuestiones de Derecho de familia, como la asistencia social de todo tipo que debe prestar la Administración pública a dicha institución.

En definitiva, en el actual sistema, las responsabilidades se comparten entre la familia y los poderes públicos. En este sentido, el artículo 39 del texto constitucional atribuye tanto a los progenitores como a los poderes públicos la responsabilidad de brindar asistencia y protección a los menores. Por un lado, los poderes públicos tienen la responsabilidad de diseñar e implementar políticas públicas y planes nacionales de infancia dirigidos a garantizar la plena efectividad de sus derechos, tanto en los aspectos personales como sociales, en el ámbito de la familia, la salud, la educación, la justicia, la cultura, el consumo o el ocio. Por otra parte, nuestro Ordenamiento jurídico encomienda de manera preferente a los progenitores la obligación de prestar, en el seno de la familia, determinadas funciones encaminadas a dar efectividad a los derechos fundamentales de los menores.

12 BORRAS RODRÍGUEZ, Alegría, «El interés del menor como factor de progreso y unificación del Derecho internacional privado", en su discurso de ingreso en la Academia de Jurisprudencia y Legislación de Cataluña, Revista Jurídica de Cataluña, n. ${ }^{\circ}$ 4, 1994, pág. 965 , considera que la superación de la distinción entre lo público y lo privado es patente en esta materia - refiriéndose a los derechos de la infancia-. Para esta autora es importante el hecho de que la cuestión ahora no se encuentra en el estricto ámbito de lo tradicionalmente denominado "privado», sino que hay una fuerte incidencia de la actividad pública, lo cual ha forzado también la evolución de la materia. Así, una cuestión perteneciente tradicionalmente al ámbito de la familia, cual es la protección de los menores, dispone ahora de una amplia proyección de carácter público, en atención, precisamente, al interés superior del menor, que excede del círculo estrictamente familiar. A esta misma conclusión llega FERNÁNDEZ MASÍA, Enrique, «Las entidades públicas y la protección de los menores extranjeros en España», Actualidad Civil, n. ${ }^{\circ} 19$, mayo, 1998, págs. 427-428, al considerar que las formas de protección de los menores han sufrido una profunda transformación en las últimas décadas reflejándose, básicamente, en la creciente acentuación de la dimensión pública frente a la puramente privada, en la mayoría de los Ordenamientos jurídicos. 
Así, a pesar de tratarse de un ámbito en el que coexisten dos ordenamientos distintos -que, además, responden a principios en muchas ocasiones antagónicos-, debe recalcarse el carácter subsidiario de la actuación pública respecto de lo que son las responsabilidades que, en primer término, corresponden a quienes tienen a los menores a su cargo. Ahora bien, las Administraciones públicas no son del todo ajenas a esta tarea privada, sino que se les reserva el deber de colaborar con la familia con el fin de favorecer y hacer posible en todo caso que los progenitores, tutores o guardadores cumplan con sus obligaciones hacia los niños y los adolescentes.

Además, de colaborar con la familia en el ejercicio de sus funciones de asistencia y protección de los menores, las Administraciones públicas quedan obligadas a velar para que dicho encargo se haga efectivo. De tal manera que, sólo en tanto éstos - progenitores, tutores, o guardadores - falten al cumplimiento de sus deberes respecto del menor, se aplicarán las medidas de protección pública previstas legalmente ${ }^{13}$.

\subsection{LAS LEYES REFORMADORAS DEL DERECHO DE LA PERSONA Y DE LA FAMILIA DEL PERÍODO 1981-1987}

La familia ha sufrido incesantes reformas en la última década que parcialmente se han visto influenciadas por la reivindicación de los derechos del niño. La Ley de 13 de mayo de 1981 reformó el Código Civil en materia de patria potestad, reconociendo al menor de edad capacidad para el ejercicio de los derechos de la personalidad, y ampliando su participación mediante la audiencia ante diversos aspectos familiares y contractuales, al mismo tiempo que suprimió la distinción entre filiación legítima e ilegítima e introdujo la investigación de la paternidad. La Ley de 7 de julio de 1981 (comúnmente conocida como «Ley del divorcio») introdujo asimismo la audiencia de los menores «si tienen suficiente juicio» y, en todo caso, cuando son mayores de 12 años.

${ }^{13}$ DE PALMA DEL TESO, Ángeles, «La protección de los menores por las administraciones públicas», Revista Jurídica de Cataluña, n. ${ }^{\circ} 2,2004$, pág. 41 , considera que la actuación administrativa protectora se guía por el principio de subsidiariedad progresiva, esto es, el alcance e intensidad de la intervención de las Administraciones públicas vendrá condicionado por el grado de desatención o desprotección que sufra el menor en el seno de su familia. Para ALBERDI, Inés, "La nueva familia española», Ed. Taurus, Madrid, 1999, págs. 56 y 68-71, la familia ya no es la única institución responsable de la infancia y los servicios sociales asumen de forma subsidiaria estas responsabilidades en caso de que aquélla desaparezca o no cumpla con sus obligaciones. 
Nos encontramos, por tanto, ante un nuevo esquema legal de relaciones paterno/materno-filiales basado en un modelo familiar participativo y en el principio del interés superior del niño. Ello implica sustituir el concepto todavía influyente de patria potestad por el de responsabilidad parental.

También la mirada pública sobre el abandono de los menores ha cambiado de signo. La Ley 21/1987, de 11 de noviembre (mal llamada "Ley de adopción») supuso una revolución en la materia. La Ley sustituye el concepto de abandono por el concepto mucho más amplio, mucho más completo, de desamparo. Se introduce también la figura de la «tutela automática ex lege» por parte de la Administración Pública -lo que vino a suponer una administrativización de la protección de la infancia en el Estado español-. Debe destacarse, en este sentido, el debate doctrinal que suscitó tal cuestión, especialmente en lo referente a si la intervención previa de la Administración priva de la necesaria tutela judicial a un derecho tan básico como la patria potestad. Aspecto que posteriormente vino a aclarar la Ley Orgánica 1/1996, de 15 de enero, de protección jurídica del menor, al establecer como efecto de la tutela automática la mera suspensión de la patria potestad.

La Ley 21/1987 también se destaca por incorporar, por primera vez en nuestro Código civil, la figura del acogimiento, que se une al listado de medidas protectoras de la infancia en situación de desamparo y por regular todo un régimen nuevo de adopción.

Por último, destacar la previsión legal de que todas las decisiones que tome la Administración Pública en el ejercicio de sus competencias protectoras de menores de edad -resoluciones administrativas - pueden ser revisadas por los Tribunales de Justicia ordinarios -resoluciones judiciales-, así como el papel relevante que se otorga al Ministerio Fiscal como eje vertebrador de la protección socio-jurídica de las personas menores de edad, en todas sus manifestaciones.

A partir de este mismo escenario, queda claro que el espíritu de la Ley ha cambiado en algo fundamental; el carácter asistencialista que tenía la legislación anterior, aquí, se pierde. El artículo 172 del Código civil, en su nueva redacción, señala de manera expresa que la primera finalidad del órgano tutor de la Comunidad Autónoma, es procurar la reincorporación del menor a su familia de origen. Ya no se trata únicamente de prevenir el riesgo o de separar al niño o niña de la situación difícil en la que pudiera encontrarse, sino de que reparado el daño que haya podido sufrir, se le busque una alternativa de vida, priorizando el retorno a su familia de origen, y si ello no es posible a través del acogimiento o de la adopción. 


\subsection{LA LEY ORGÁNICA 1/1996, DE 15 DE ENERO, DE PROTECCIÓN JURÍDICA DEL MENOR}

Finalmente, la última escala de este itinerario en torno a los derechos del menor lo constituye la aprobación por parte del legislador español de la controvertida Ley Orgánica 1/1996, de 15 de enero.

El nuevo espíritu que late en las anteriores normas se condensa en el artículo 2.2 de la Ley Orgánica 1/1996, de 15 de enero: «Las limitaciones a la capacidad de obrar de los menores se interpretarán de forma restrictiva», principio no exento de complejidad. Se da aquí lo que expresivamente se tituló «contradicción entre paternalismo y liberalismo». En primer lugar porque, por un lado, se hace un reconocimiento general a la capacidad del menor, disponiendo que las incapacidades se interpreten de forma restrictiva, y por otro, se coarta esa libertad e imponen limitaciones a su capacidad de obrar en aquellos aspectos que al legislador, llevado por su afán proteccionista, le parece que deben intervenir los poderes públicos, incluso contradiciendo la voluntad tanto del menor como del propio legislador. Esta incoherencia se comprueba en el propio articulado de la ley ${ }^{14}$.

Puede afirmarse que la Ley Orgánica 1/1996, de 15 de enero, de protección jurídica del menor, ha venido a profundizar en los principios de protección integral del menor y del superior interés de aquél al sintonizar con la nueva filosofía surgida de la Convención de los Derechos del Niño, de las Naciones Unidas, de 30 de noviembre de $1989^{15}$, que ha dejado su impronta no sólo en el marco internacional

${ }_{14}$ Una muestra significativa es la del derecho de asociación del menor (artículo 7.) del que se ha dicho que no se sabe si tienen o no capacidad, y cuál es el ámbito de la misma. NÚÑEZ MUÑIZ, C., "Algunas consideraciones sobre la Ley Orgánica 1/1996, de 15 de enero, de protección jurídica del menor", en la Ley n. ${ }^{\circ} 4135$, Octubre 1996.

15 En este sentido se pronuncia VARELA GARCÍA, Carlos, "Comentarios a la Ley Orgánica 1/1996, de 15 de enero de protección jurídica del menor: principios programáticos y normas de conflicto", Actualidad Civil n. ${ }^{\circ} 12$, marzo, 1997, pág. 266, quien manifiesta que la Ley Orgánica 1/1996, de 15 de enero, reconoce a los menores todos los derechos fundamentales inherentes a la persona, sin perjuicio de la protección integral a que se refiere la Ley; por su parte NÚÑEZ MUÑIZ, Carmen, «Algunas consideraciones sobre la Ley Orgánica 1/1996, de 15 de enero, de protección jurídica del menor, La Ley, Vol. 5, n. ${ }^{\circ} 4135$, octubre, 1996, pág. 1483, afirma que la Ley Orgánica 1/1996, de 15 de enero, supone un paso más en esta evolución - se refiere a los derechos de la infancia-, y trata de hacerse eco del distinto status social del niño como consecuencia de las transformaciones sociales y culturales operadas en nuestra sociedad; también LEAL PÉREZ OLAGU, M. ${ }^{\mathrm{a}}$ Luisa, "Comentarios a la Ley Orgánica 1/1996, de 15 de enero, de protección jurídica del menor, de modificación parcial del Código Civil y de la Ley de Enjuiciamiento Civil», La Ley, Vol. 2, n. ${ }^{\circ} 3986$, marzo, 1996, pág. 1310, defiende que en España durante los últimos años se ha incrementa- 
sino también en muchas de las políticas sociales y educativas del menor en el interior de algunos países europeos. Particularmente, la Ley española reconoce a los menores como titulares de una serie de derechos y, entre ellos; el "derecho a ser oído" en todos aquellos procesos administrativos o judiciales que le afecten.

Por su relevancia para proteger el interés del menor, que no siempre será coincidente con el de los adultos, el artículo 9 regula el derecho de aquél a ser oído no sólo en el ámbito familiar sino en cualquier procedimiento administrativo o judicial que vaya a afectarle. A pesar de reconocer el legislador la categoría de derecho al interés del menor a ser escuchado; paradójicamente añade en el apartado 3 de este artículo que puede verse privado de este derecho el menor aunque él mismo hubiese solicitado ejercerlo, conformándose con establecer la paupérrima cautela de que en tal caso la denegación «será motivada y comunicada al Ministerio Fiscal».

También la Ley de 1996 introduce por primera vez en nuestro Ordenamiento jurídico la diferencia, dentro de las situaciones de desprotección social de la infancia, entre situaciones de riesgo (artículo 17) y situaciones de desamparo (artículo 18), que dan lugar a distintos grados de intervención de la Entidad Pública.

\section{BIBLIOGRAFÍA}

Alonso PÉREz, Mariano, «La situación jurídica del menor en la Ley Orgánica $1 / 1996$, de 15 de enero, de protección jurídica del menor, de modificación del Código Civil y de la Ley de Enjuiciamiento Civil: luces y sombras», en Actualidad Civil, n. ${ }^{\circ}$ 2, Enero 1997.

ARIÈs, Philippe, «El niño y la vida familiar en el Antiguo Régimen», versión castellana de Naty García Guadilla, Ed. Taurus, Madrid, 1987.

BALLESTEROS DE LOS Ríos, María, «El desamparo y la tutela automática de las Entidades Públicas», Ed. Tecnos, Madrid, 1997.

BORRÁs, Alegría, «El interés del menor como factor de progreso y unificación del Derecho internacional privado", en su discurso de ingreso en la Academia de Jurisprudencia y Legislación de Cataluña, Revista Jurídica de Cataluña, n. ${ }^{\circ} 4,1994$.

do la demanda social para incorporar los principios de la Convención a nuestro derecho positivo, impulsando un instrumento legislativo que contemple al menor como sujeto de los derechos constitucionalmente reconocidos; finalmente, PICONTÓ NOVALES, Teresa, "La protección de la infancia. Aspectos sociales y jurídicos", Ed. Egido, Zaragoza, 1996, pág. 93, considera que la Ley Orgánica 1/1996, de 15 de enero, ha profundizado en los principios de protección integral y del superior interés del menor al sintonizar con la nueva filosofía de sus derechos, surgida al calor de la Convención de 1989. 
CASAS, Ferran, «Infancia: perspectivas psicosociales», Ed. Paidós, Barcelona, 1998.

COTS I MONER, Jordi, «La Declaració Universal dels Drets de l'Infant», Estudis. Rosa Sensat, Edicions 62, Barcelona, 1979.

CYRULNIK, Boris, "Los patitos feos. La resiliencia: una infancia infeliz no determina la vida", Ed. Gedisa, Barcelona, 2002.

De Palma DEL Teso, Ángeles, «La protección de los menores por las Administraciones Públicas», en Revista Jurídica de Cataluña, n. ${ }^{\circ}$ 2, 2004.

Demause, Lloyd, "Historia de la Infancia», Ed. Alianza Universidad, Madrid 1982.

FERnÁNDEZ MASÍA, Enrique, "Las entidades públicas y la protección de los menores extranjeros en España», en Actualidad Civil, n. ${ }^{\circ}$ 19, Mayo 1998.

Giménez SaLINAS, Esther, «Protección de Menores» en "Comentarios al Estatuto de Autonomía de Cataluña», Vol. II, Ed. Instituto de Estudios Autonómicos, Barcelona, 1990.

Gómez Granell, Carme (Dir.), «La infancia en cifras España», Ed. Ministerio de Trabajo y Asuntos Sociales, Madrid, 2006.

Leal Pérez Olagu, M. ${ }^{a}$ Luisa, «Comentarios a la Ley Orgánica 1/1996, de 15 de enero, de protección jurídica del menor, de modificación parcial del Código Civil y de la Ley de Enjuiciamiento Civil», en La Ley, Vol.2, n. ${ }^{\circ}$ 3986, 1996.

LinAzA, Josetxu, «Desarrollo, educación y derechos de la infancia», en Infancia y Sociedad, n. ${ }^{\circ} 27-28$, Octubre 1994.

MELIÁ LLÁCER, Reyes, "La protección internacional de los Derechos de los Niños», Revista General del Derecho, n. ${ }^{\circ}$ 536, Volumen II, 1989.

Newell, Peter y Hodgkin, Rachel «Implementation Handbook for the Convention on the Rights of the Child", Ed. Unicef, New York, 1998.

Núñez MuÑIZ, C., «Algunas consideraciones sobre la Ley Orgánica 1/1996, de 15 de enero, de protección jurídica del menor», en la Ley n. ${ }^{\circ} 4135$, Octubre 1996.

Picontó Novales, Teresa, «La protección de la infancia. Aspectos sociales y jurídicos», Ed. Egido, Zaragoza, 1996.

Roca TRIAS, Encarna, «Familia y cambio social (De la casa a la persona)», Ed. Cuadernos Civitas, Barcelona, 1999.

ROCA TRIAS, Encarna, "El nuevo derecho catalán sobre la familia», en Revista Jurídica de Cataluña, n. ${ }^{\circ} 1,1999$.

VARELA GARCIA, A., "Comentarios a la Ley Orgánica 1/1996, de protección jurídica del menor: principios programáticos y normas de conflicto», en Actualidad Civil, n. ${ }^{\circ} 12$, Marzo de 1997.

VEERMAN, P. E., "The rights of the child and the changing image of childhood», Ed. Martinus Nijhoff, Dordrecht, 1992.

VERHELLEN, Eugeen, "Convention on the Rights of the Child», Garant Publishers, Gent, 1997.

VILLAGRASA ALCAIDE, Carlos, "Infancia y legislación» en GÓMEZ GRANELL, Carme (Coord.), "La infancia y las familias a inicios del siglo XXI», Ed. Instituto de Infancia y Mundo Urbano, Vol. 5, Barcelona, 2002. 